\title{
Influence of contact pressure and sliding speed dependence on the tribological characteristics of an activated carbon- epoxy composite derived from palm kernel under dry sliding conditions
}

\author{
Dayang Nor Fatin MAHMUD ${ }^{1}$, Mohd Fadzli Bin ABDOLLAH ${ }^{1,2,}$, Nor Azmmi Bin MASRIPAN ${ }^{1,2}$, Noreffendy \\ TAMALDIN $^{1,2}$, Hilmi AMIRUDDIN ${ }^{1,2}$ \\ ${ }^{1}$ Faculty of Mechanical Engineering, Universiti Teknikal Malaysia Melaka, Hang Tuah Jaya, Durian Tunggal, Melaka 76100, Malaysia \\ ${ }^{2}$ Centre for Advanced Research on Energy, Universiti Teknikal Malaysia Melaka, Hang Tuah Jaya, Durian Tunggal, Melaka 76100, Malaysia \\ Received: 18 June 2017 / Revised: 06 December 2017 / Accepted: 22 December 2017
}

(C) The author(s) 2018. This article is published with open access at Springerlink.com

\begin{abstract}
The objective of this work is to investigate the influence of contact pressure and sliding speed on the coefficient of friction and wear of an activated carbon-epoxy composite derived from palm kernel under dry sliding conditions. A wear mode map approach was employed to identify the transitions from mild to severe wear of the composite. The dry sliding test was executed by utilizing a ball-on-disc tribometer at different contact pressures and sliding speeds with a constant sliding distance and operating temperature. The results showed that, regardless of the sliding speed, the friction coefficient and wear rate of the composite increased drastically when a critical limit of contact pressure is exceeded. As for the sliding speed, both the friction coefficient and wear rate increased first and thereafter decreased at a higher speed of $500 \mathrm{rpm}$. A wear mode map is proposed to classify the boundary from mild to severe wear regimes. The predominant wear failures identified include micro-crack, fine grooves, debonding, delamination, debris, broken carbon, and fracture.
\end{abstract}

Keywords: activated carbon; agriculture waste; palm kernel; friction and wear; pressure and speed

\section{Introduction}

Nowadays, many alternative technologies including thin film coatings [1-4], green lubricants [5-9], and bio/eco-materials [10-13] have been introduced for sustainability owing to the global need to save energy by reducing the friction and wear of components or parts.

Globally, Malaysia is one of the largest producers and exporters of palm oil, accounting for $11 \%$ of the world's oil and fat production, and $27 \%$ of the export trade of oils and fats. The palm oil industry generates a large quantity of waste consisting of approximately $90 \%$ of biomass waste and only approximately $10 \%$ of palm oil [14]. The use of agricultural waste as a new composite material has been observed to be renewable and relatively less expensive and ultimately could transform the waste effectively into wealth [15-17]. Therefore, this motivated us to investigate the potential of activated carbon derived from one of the largest wastes in the extraction of palm oils, called palm kernel, as a new tribological material. The palm kernel activated carbon, also known as palm oil extraction waste material, is composed of a carbonaceous, highly porous adsorptive medium with a similar atomic structure as graphite, but in a disorganized form [18]. Furthermore, this activated carbon in the form of composite has immense potential to be a self-lubricating material with a low friction coefficient and high wear resistance owing to the

* Corresponding author: Mohd Fadzli Bin ABDOLLAH, E-mail: mohdfadzli@utem.edu.my 
presence of remaining natural oils in the palm kernel [19-21]. In addition, Tahir et al. [19] observed that there was no significant impact of sliding distance on the friction coefficient of a palm kernel activated carbon reinforced polymer composite. However, a change in working temperature was observed to influence its tribological performances. Chua et al. [22] discovered that there is a potential use of the palm kernel activated carbon reinforced with polymer composite as a lubricant in solid state, which can reduce the friction coefficient and wear owing to the applied load.

There were few research studies that reported the effects of operating conditions on the tribological characteristics of an activated carbon-epoxy composite derived from palm kernel, such as applied load, temperature, and sliding distance. However, studies on the simultaneous effects of contact pressure and sliding speed are limited to exploring the tribological characteristics of an activated carbon-epoxy composite derived from palm kernel. Thus, the aim of this study is to investigate the influence of contact pressure and sliding speed on the friction coefficient and wear of an activated carbon-epoxy composite derived from palm kernel under dry sliding conditions. Furthermore, a wear mode map of the composite is proposed to identify the transition points from mild to severe wear and their correlation with contact pressure and sliding speed.

Tabor [23] discovered the idea of a wear map and was inspired by the innovative work of Frost and Ashby [24] on deformation maps. The development of a wear map is a useful way to study and represent mild to severe wear transitions of two materials sliding against one another under different parameters. Studies have demonstrated that wear failure changes with the severity of contact conditions [25]. Until now, there was no specific outline to develop a wear mode map, because the controlling variables vary with mechanism or parameter. Generally, the construction of wear mode maps can be divided into two types, involving empirical and physical modeling [26, 27]. Empirical data from experiments are plotted on appropriate axes and identified by the wear rate. Boundaries are drawn to separate classes of wear failure. Physical modeling consists of model-based equations, describing the wear rate caused by each mechanism. However, only the empirical approach is used in this study.

\section{Methodology}

\subsection{Material preparation}

For preparing the specimens, the material used in this study is activated carbon derived from palm kernel, which is waste from the palm oil extraction process. Palm oil is composed of exocarp, mesocarp, endocarp, and endosperm. However, in the extraction process undertaken by the manufacturer, only the endocarp part, also known as the kernel, is used, which becomes activated carbon derived from palm kernel.

As shown in Fig. 1, a disc of diameter $74 \mathrm{~mm}$ and thickness $5 \mathrm{~mm}$ was produced by mixing $60 \mathrm{wt} . \%$ activated carbon derived from palm kernel (particle size $250 \mu \mathrm{m}$ ) with $40 \mathrm{wt}$ \% epoxy, where the hardener to resin ratio is $1: 4$. The mixture was thereafter placed in a mold and pressed using a hot-press machine at a forming temperature and pressure of $80{ }^{\circ} \mathrm{C}$ and $2.5 \mathrm{MPa}$, respectively. The green composite was thereafter cured at room temperature of $23^{\circ} \mathrm{C}$ for one week.

The hardness, density, and surface roughness of the materials were measured using a Type D shore hardness tester, densitometer, and profilometer, respectively. The Young's modulus was determined using a tensile test.

\subsection{Tribological test}

The dry sliding experiment was performed utilizing a ball-on-disc tribometer (Fig. 2), in accordance with

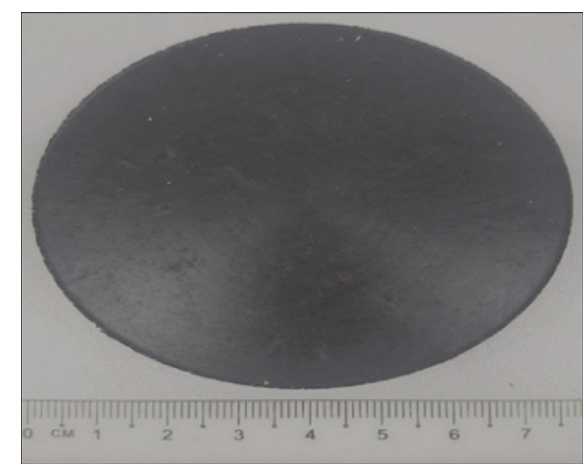

Fig. 1 Disc specimen of an activated carbon-epoxy composite derived from palm kernel. 


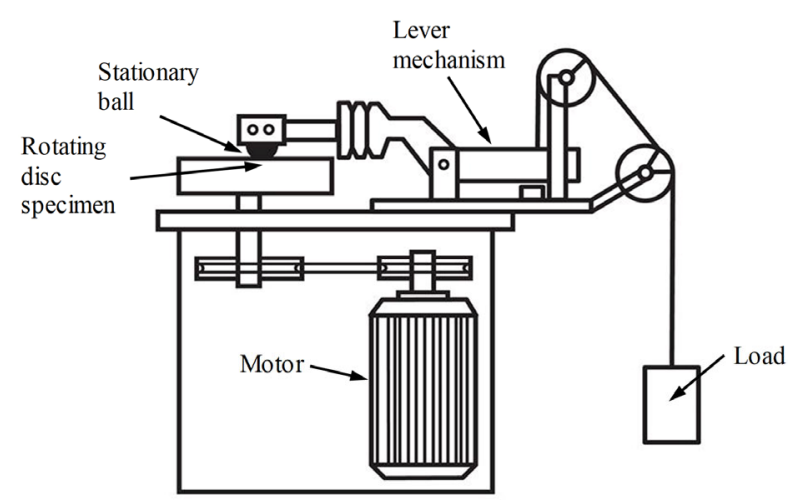

Fig. 2 Schematic diagram of a ball-on-disc tribometer.

ASTM G99-05 [28]. All the tests were performed at different applied loads between 20 and $100 \mathrm{~N}$, with a sliding speed in the range $200-500 \mathrm{rpm}$ at a constant sliding distance of 3,000 $\mathrm{m}$. The operating temperature was $27^{\circ} \mathrm{C}$. ASTM 52100 (EN31) chrome steel ball, as a counter surface, with two different diameter sizes $10 \mathrm{~mm}$ and $12.7 \mathrm{~mm}$, was used in this study. Each test was repeated three times to reduce the experimental errors.

The nominal contact pressure, $P_{\mathrm{m}}$, was calculated based on the Hertzian theory using Eqs. (1) and (2).

$$
\begin{gathered}
a=\left(\frac{3 W R}{4 E^{*}}\right)^{1 / 3} ; \frac{1}{E^{*}}=\frac{1-v_{1}^{2}}{E_{1}}+\frac{1-v_{2}^{2}}{E_{2}} \\
P_{\mathrm{m}}=\frac{W}{2 \pi a^{2}}
\end{gathered}
$$

where $a$ is the contact radius (m), $W$ is the applied load $(\mathrm{N}), R$ is the radius of the ball $(\mathrm{m}), E^{*}$ is the effective Young's modulus ( $E_{1}=$ Young's modulus of the disc; $E_{2}=$ Young's modulus of the ball), $v$ is the Poisson's ratio $\left(v_{1}=\right.$ Poisson's ratio of the disc; $v_{2}=$ Poisson's ratio of the ball), and $P_{\mathrm{m}}$ is the nominal contact pressure $(\mathrm{Pa})$.

The friction coefficient, $\mu$, was calculated using Eq. (3).

$$
\mu=\frac{F}{W}
$$

where $F$ is the frictional force $(\mathrm{N})$.

The test composite wear data were obtained by measuring the initial and final disc masses via the ballon-disc test. The specific wear rate, $k$, was calculated using Eqs. (4) and (5).

$$
\begin{aligned}
& V_{\text {loss }}=\frac{m_{\text {loss }}}{\rho} \\
& k=\frac{V_{\text {loss }}}{(W \times L)}
\end{aligned}
$$

where $V_{\text {loss }}$ is the loss of volume $\left(\mathrm{mm}^{3}\right), m_{\text {loss }}$ is the loss of mass $(\mathrm{g}), \rho$ is the density $\left(\mathrm{g} / \mathrm{mm}^{3}\right), k$ is the specific wear rate $\left(\mathrm{mm}^{3} /(\mathrm{N} \cdot \mathrm{mm})\right)$, and $L$ is the sliding distance (m).

A summary of the operating parameters used in this study is presented in Table 1 . The physicalmechanical properties of both disc and ball are listed in Table 2.

\subsection{Development of wear mode map}

In this study, an empirical approach was used to develop a wear mode map, where suitable axes of the map were to be decided. The appropriate axes were determined to be the sliding speed and nominal contact pressure.

All the experimental wear data were plotted on two different graphs as a function of the sliding speed and nominal contact pressure. Subsequently, the locations of wear transitions were identified using experimental observations and data trend analysis. Arrows indicate the onset of these wear transitions. The best fitting curves connecting all the transition

Table 1 The operating parameters for the dry sliding test.

\begin{tabular}{ccc}
\hline Test parameter & Unit & Value \\
\hline Applied load, $W$ & $\mathrm{~N}$ & $20,40,60,80,100$ \\
Ball's diameter, $d$ & $\mathrm{~mm}$ & $10.0,12.7$ \\
Sliding speed, $N$ & $\mathrm{rpm}$ & $200,300,400,500$ \\
Sliding distance, $L$ & $\mathrm{~m}$ & 3,000 \\
\hline
\end{tabular}

Table 2 Physical-mechanical properties of the ball and disc materials before testing.

\begin{tabular}{ccc}
\hline 'Properties & $\begin{array}{c}{ }^{\mathrm{a}} \text { Disc (60 wt.\% } \\
\text { activated carbon }+ \\
\text { 40 wt.\% epoxy) }\end{array}$ & $\begin{array}{c}{ }^{\mathrm{b}} \text { ASTM 52100 } \\
(\mathrm{EN31)} \text { chrome } \\
\text { steel ball }\end{array}$ \\
\hline Hardness, $H$ & $8.36 \mathrm{GPa}$ & $7.45 \mathrm{GPa}$ \\
Young Modulus, $E$ & $7.61 \mathrm{GPa}$ & $210 \mathrm{GPa}$ \\
Poisson's ratio, $v$ & 0.23 & 0.3 \\
Density, $\rho$ & $1.4 \mathrm{~g} / \mathrm{cm}^{3}$ & $7.81 \mathrm{~g} / \mathrm{cm}^{3}$ \\
Surface roughness, $R_{\mathrm{a}}$ & $0.4 \mu \mathrm{m}$ & $0.022 \mu \mathrm{m}$ \\
\hline
\end{tabular}

${ }^{a}$ Properties from laboratory measurements.

${ }^{\mathrm{b}}$ Properties from manufacturer. 
points were thereafter traced and illustrated on the graph of a wear mode map (sliding speed vs. nominal contact pressure). These curves represent the mild to severe wear transition boundary of the material.

\subsection{Surface morphology observation}

The surface morphology of the worn surfaces was observed using scanning electron microscopy (SEM). In addition, the chemical composition was determined using energy-dispersive $\mathrm{X}$-ray spectroscopy (EDX).

\section{Results and discussion}

\subsection{Friction coefficient and wear rate properties}

Figure 3 presents the data on the friction coefficient and wear rate of an activated carbon-epoxy composite derived from palm kernel. It can be observed that, at the beginning, the friction coefficient decreases with contact pressure, although the wear rate remains almost constant. Subsequently, at a certain level of contact pressure, the friction coefficient and wear rate increase significantly. This could indicate that, when the contact pressure was raised, the real surface contact area also increased, causing more plastic deformation to the asperities, resulting in energy dissipation. This caused the frictional force to increase, while maintaining the wear rate. This study used Coulomb's friction law $F=\mu W$. The law was originally defined in a general per area form: $\tau=\mu q$, where $\tau$ is the friction per area and $q$ is the normal pressure. This law is only applicable at low normal pressures. When the frictional force continues to increase, the rate (friction coefficient) at which it increases with respect to normal load decreases. Applying additional pressure, therefore, cannot flatten asperities further, and the contact area is constant at higher pressure. Therefore, friction should remain constant for higher pressure, as the law states, and only depend on the material strength. However, when the contact pressure increases to the critical limit, the friction coefficient and wear rate rise drastically owing to the critical surface energy. This could be explained by the fact that the frictional heat raises the temperature of the friction surfaces, which leads to a reduction in the material strength and will eventually result in surface softening
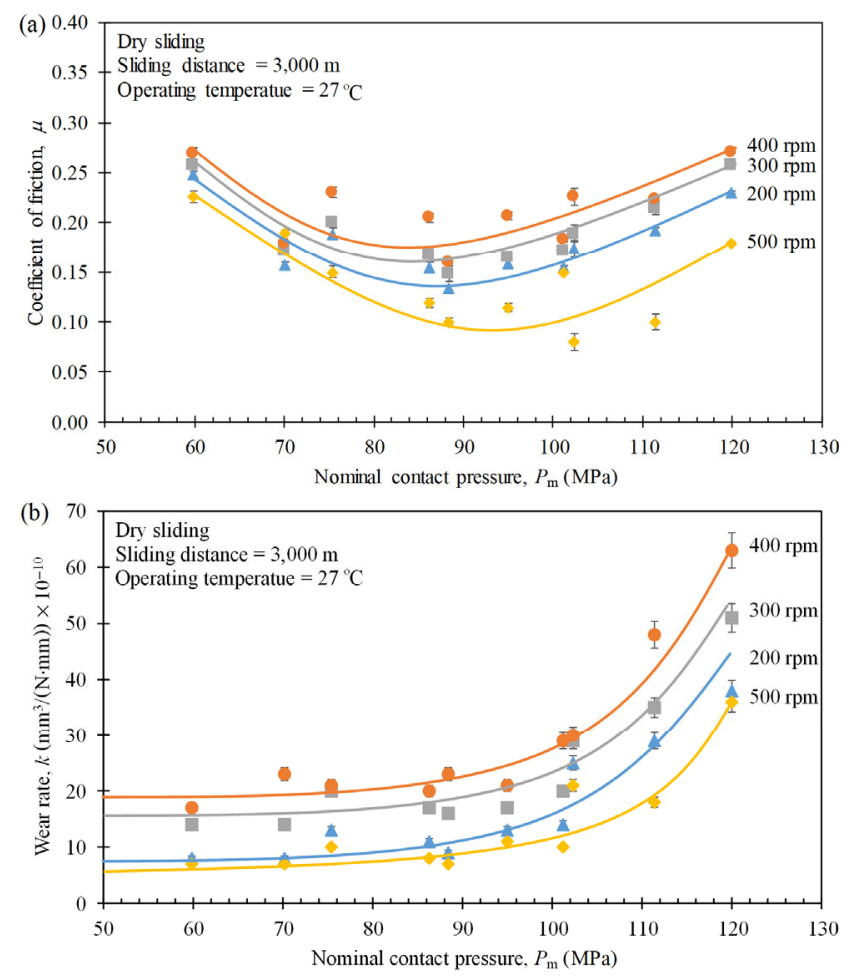

Fig. 3 Effect of contact pressure on the (a) friction coefficient and (b) wear rate of an activated carbon-epoxy composite derived from palm kernel at different sliding speeds. The error bar is for the standard deviation.

of the polymer composite or a decreased hardness of the composite, as discussed in our previous publication [29].

As for the sliding speed, both the friction coefficient and wear rate increase first and thereafter decrease at a higher speed of $500 \mathrm{rpm}$. This is due to frictional heating as discussed above. However, at a higher sliding speed of $500 \mathrm{rpm}$, there is a significant decrease in the friction coefficient and wear rate. Raising the sliding speed results in increasing the surface temperature, which reduces the adhesion between the composite surfaces and steel ball [30]. This behavior can be rationalized within the frame of the adhesive theory of friction to provide better self-lubrication and protection to surfaces. This can be explained by the fact that the tribolayer, produced by the initial wear of the carbon substance, was caused by a tribofilm adhering to the contact surface, which dissolves the adhesive joints between the asperities [31,32]. From Fig. 4(a), the formation of a transfer layer, as observed on the counter surfaces, could have accounted for the decrease in friction coefficient and wear rate owing to 

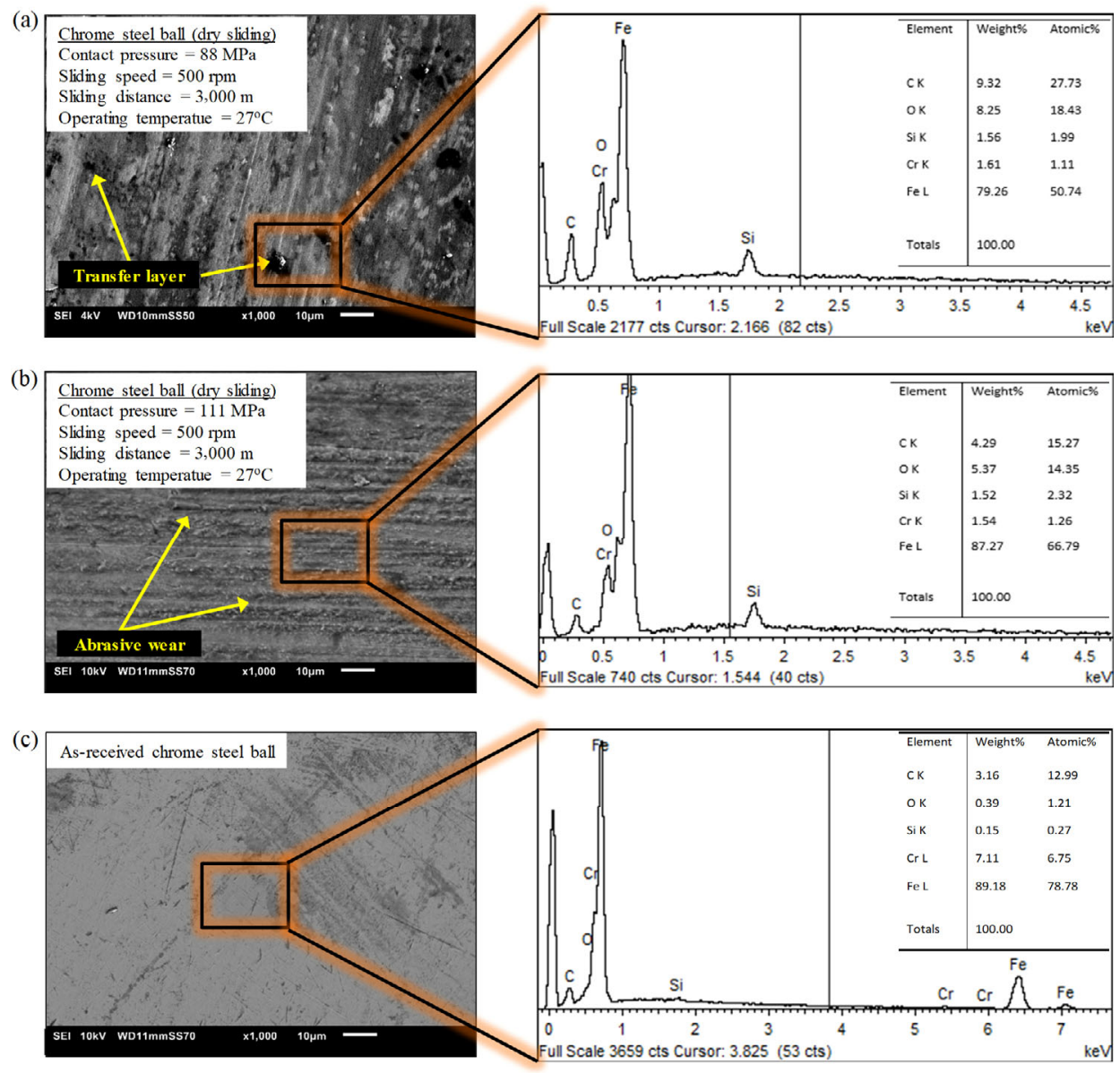

Fig. 4 SEM micrograph and EDX spectrum of the counter surfaces (a) tested at $88 \mathrm{MPa}$, (b) $111 \mathrm{MPa}$, and (c) as-received chrome steel ball.

the surface contact changes from carbonized-steel to carbonized-carbonized materials. Another possible explanation for the increase in the friction coefficient and wear rate, at a certain level of contact pressure for the sliding speed of $500 \mathrm{rpm}$, is the deterioration of this transfer layer, thus forcing the counter surface of the protective layer to disappear. This also signifies that the contact surface has experienced high abrasion owing to the ploughing between the contact surfaces, which might have influenced the increment of the friction force and wear rate [33]. Figure 4(b) shows a higher-magnification micrograph of the damaged regions, where abrasive wear starts materializing on the counter surface. Consequently, this may have caused the increase in the friction coefficient and wear rate of the composite at contact pressure, which led to the removal of the material. Figure 4(c) shows the SEM micrograph and EDX spectrum of the counter surface for the as-received chrome steel ball, where the carbon element is not as much as in Figs. 4(a) and 4(b).

\subsection{Wear mode map}

Figure 5 is translated from Fig. 3, where the data values are separated by each sliding speed in order to trace the transition points from mild to severe wear. Figure 6(a) presents the wear mode map for the activated carbon-epoxy composite derived from palm kernel. It was developed based on transition points from the wear rate values as shown in Fig. 5. In this study, the wear mode map can be divided into two regimes: mild wear and severe wear. In the mild wear regime, the values of wear rates are relatively low and the surface damages are mild; in the severe wear regime, the wear rates are relatively high and the surface damages are severe [34]. From the wear mode map, regardless of the sliding speed, it was observed 

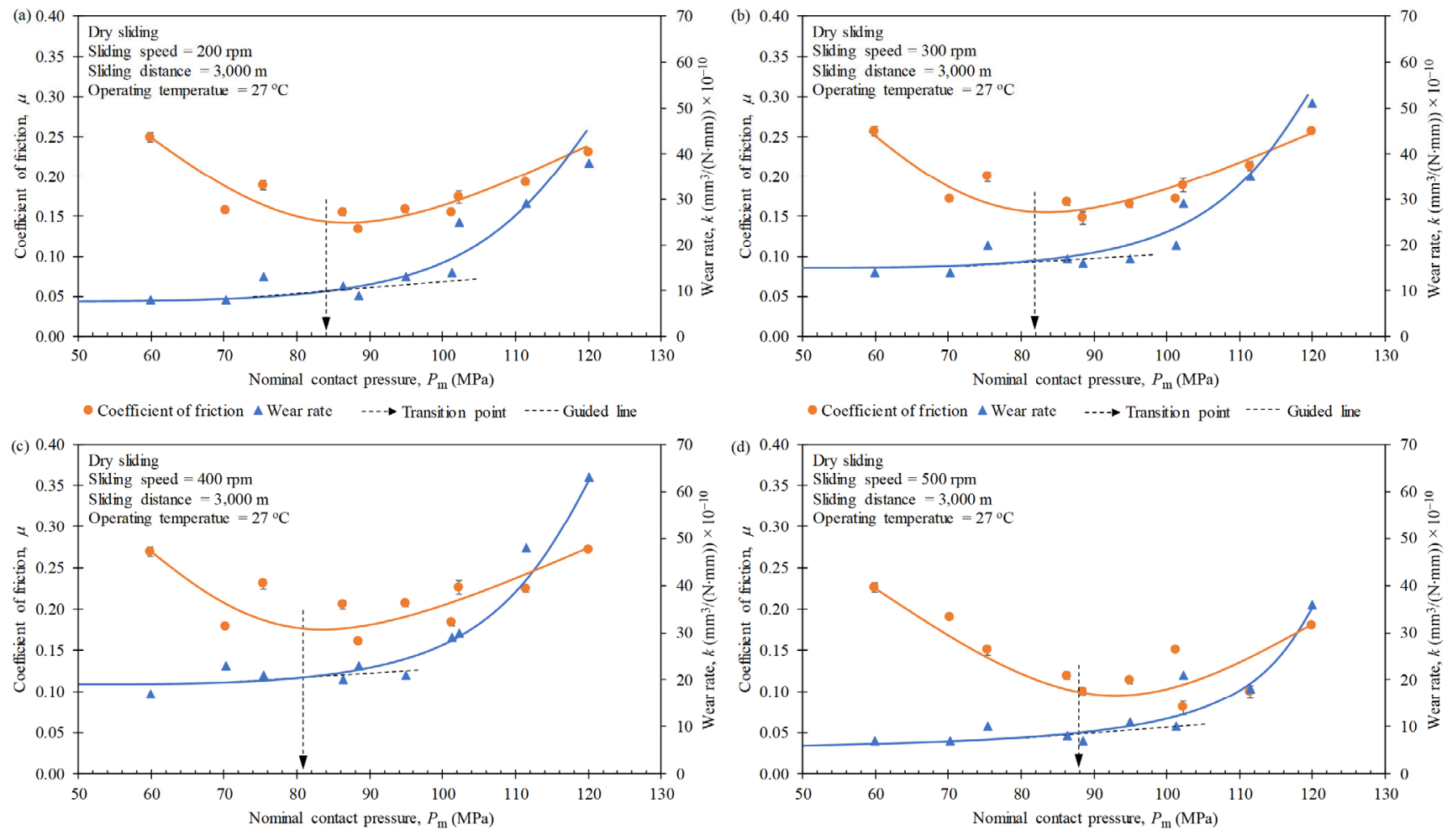

- Coefficient of friction $\Delta$ Wear rate $\quad-\cdots$ Transition point $\quad---$ - Guided line

- Coefficient of friction $\Delta$ Wear rate $\quad \cdots \rightarrow$ Transition point $\cdots$-.-- Guided line

Fig. 5 Transition points from mild to severe wear of an activated carbon-epoxy composite derived from palm kernel at different sliding speeds of (a) $200 \mathrm{rpm}$, (b) $300 \mathrm{rpm}$, (c) $400 \mathrm{rpm}$, and (d) $500 \mathrm{rpm}$. The error bar is for the standard deviation.

that increasing the value of contact pressure led to severe wear. When the composite operated at a higher level of sliding speed, the transitions from mild to severe wear occurred at lower contact pressure. However, after $400 \mathrm{rpm}$, a considerably slow change from mild to severe wear occurred, where the composite material showed better wear performance. This mild to severe wear transition was further confirmed by worn surface morphology.

Figure 6(b) shows the SEM micrograph of wear failures for the activated carbon-epoxy composite derived from palm kernel in both mild and severe wear regimes. In the mild wear regime, micro-crack (marked as "Cr"), fine grooves (marked as "Fg"), and debonding (marked as " $\mathrm{Db}^{\prime}$ ) were observed. In contrast, in the severe wear regime, predominant wear failures were identified as delamination (marked as " $\mathrm{Dl}^{\prime}$ ), debris (marked as "De"), broken carbon (marked as "Bc"), or fracture (marked as "Fr"). Fracture, delamination, and breaking of carbon led to the separation of carbon and resinous regions, which resulted in higher material removal rate. Consequently, a high amount of debris was observed. Owing to the combined high action of contact surface and sliding speed, the surface of the composite generated friction, which led to the removal of wear debris. Moreover, a further increase in the sliding speed and contact pressure led to an increase in the temperature, which resulted in surface softening and elastic-plastic deformation, changing to plastic formation [35]. Thus, the severe wear manifested itself as massive surface damage accompanied by the generation of fine debris particles.

Figure 7 shows the most recent studies on the tribological performance of commercial and other agricultural waste-based polymeric composites for the purpose of comparison. An activated carbon-epoxy composite derived from palm kernel shows a lower friction coefficient and better wear resistance than other synthetic polymers and their composites. Moreover, the friction coefficient and wear resistant are similar to those of graphite/epoxy composite. 


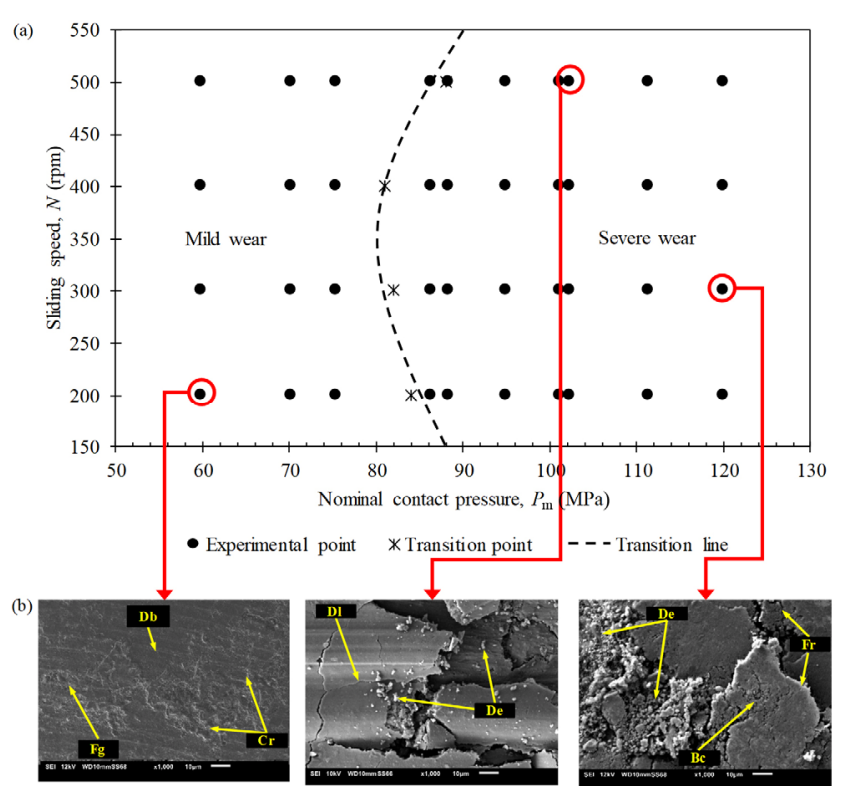

Fig. 6 (a) A wear mode map and (b) identified wear failures of an activated carbon-epoxy composite derived from palm kernel $(\mathrm{Cr}=$ micro-crack; $\mathrm{Fg}=$ fine grooves; $\mathrm{Db}=$ debonding; $\mathrm{Dl}=$ delamination; $\mathrm{De}=$ debris; $\mathrm{Bc}=$ broken carbon; $\mathrm{Fr}=$ fracture).
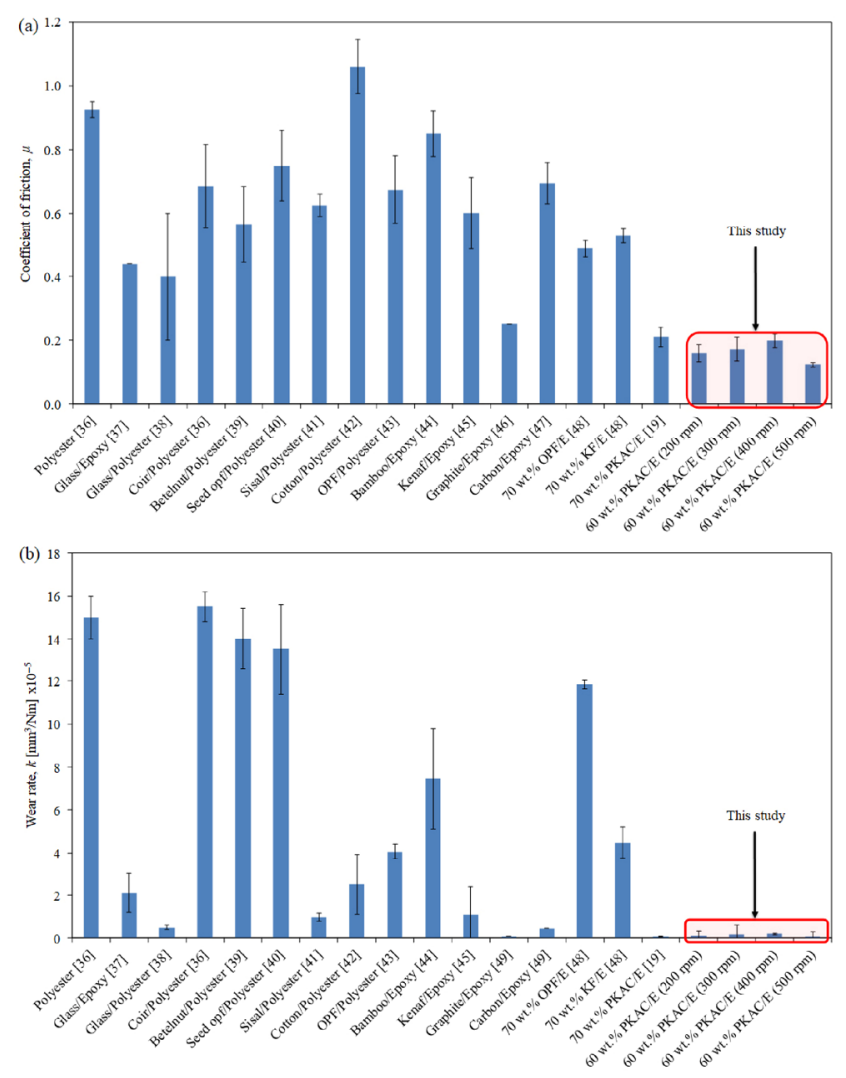

Fig. 7 (a) Coefficient of friction and (b) specific wear rate of synthetic and other agricultural waste-based polymeric composite under dry sliding conditions and tested at room temperature. The error bar is for the standard deviation. (Note: PKAC/E is an acronym for activated carbon-epoxy composite derived from palm kernel).

\section{Conclusions}

In summary, regardless of the sliding speed, initially, when the value of contact pressure increases, the friction coefficient decreases although the wear rate remains almost constant. When the contact pressure exceeds a critical limit, the friction coefficient and wear rate of the activated carbon-epoxy composite derived from palm kernel rapidly increase and lead to severe wear. However, both the friction coefficient and wear rate decrease at a higher speed of $500 \mathrm{rpm}$. Furthermore, a wear mode mapping approach was also undertaken to represent the mild to severe wear transitions. Predominant wear failures included micro-crack, fine grooves, debonding, delamination, debris, carbon broken, and fracture.

\section{Acknowledgements}

The author, Dayang Nor Fatin MAHMUD gratefully acknowledges the scholarship from MyBRAIN UTeM for his Master study. This research is supported by the grant from the Ministry of Higher Education Malaysia (Grant number: FRGS/1/2016/TK10/FKMCARE/F00315). In addition, the authors gratefully acknowledge contributions from the members of the Green Tribology and Engine Performance (G-Tribo-E) Research Group.

Open Access: The articles published in this journal are distributed under the terms of the Creative Commons Attribution 4.0 International License (http://creativecommons.org/licenses/by/4.0/), which permits unrestricted use, distribution, and reproduction in any medium, provided you give appropriate credit to the original author(s) and the source, provide a link to the Creative Commons license, and indicate if changes were made.

\section{References}

[1] Li X, Sawaki T, Kousaka H, Murashima M, Umehara N. Effect of mating materials on wear properties of amorphous hydrogenated carbon $(\mathrm{aC}: \mathrm{H})$ coating and tetrahedral amorphous carbon (ta-C) coating in base oil boundary lubrication condition. Journal Tribology 15: 1-20 (2017) 
[2] Shen B, Chen S, Chen Y, Sun F. Enhancement on the tribological performance of diamond films by utilizing graphene coating as a solid lubricant. Surface and Coatings Technology 311: 35-45 (2017)

[3] Erdemir A, Eryilmaz O. Achieving superlubricity in DLC films by controlling bulk, surface, and tribochemistry. Friction 2(2): 140-155 (2014)

[4] Abdollah M F B, Yamaguchi Y, Akao T, Inayoshi N, Tokoroyama T, Umehara N. The effect of maximum normal impact load, absorbed energy, and contact impulse, on the impact crater volume/depth of DLC coating. Tribology Online 6(6): 257-264 (2011)

[5] Shankar S, Mohanraj T, Ponappa K. Influence of vegetable based cutting fluids on cutting force and vibration signature during milling of aluminium metal matrix composites. Journal Tribology 12: 1-17 (2017)

[6] Sinha M K, Madarkar R, Ghosh S, Rao P V. Application of eco-friendly nanofluids during grinding of Inconel 718 through small quantity lubrication. Journal of Cleaner Production 141: 1359-1375 (2017)

[7] Abdullah M I H C, Abdollah M F B, Amiruddin H, Tamaldin N, Nuri N R M. The potential of hBN nanoparticles as friction modifier and antiwear additive in engine oil. Mechanics \& Industry 17(1): 104 (2016)

[8] Noorawzi N, Samion S. Tribological effects of vegetable oil as alternative lubricant: a pin-on-disk tribometer and wear study. Tribology Transactions 59(5): 831-837 (2016)

[9] Zulkifli N W M, Kalam M A, Masjuki H H, Al Mahmud K A H, Yunus R. The effect of temperature on tribological properties of chemically modified bio-based lubricant. Tribology Transactions 57(3): 408-415 (2014)

[10] Ilanko A K, Vijayaraghavan S. Wear mechanism of flax/ basalt fiber-reinforced eco friendly brake friction materials. Tribology-Materials, Surfaces \& Interfaces 11(1): 47-53 (2017)

[11] Parikh H H, Gohil P P. Experimental investigation and prediction of wear behavior of cotton fiber polyester composites. Friction 5(2): 183-193 (2017)

[12] Yamaguchi T, Shibata K, Hokkirigawa K. Effect of temperature on the dry sliding friction and wear of rice bran ceramics against different counterpart materials. Tribology Transactions in press, https://doi.org/10.1080/ 10402004.2017.1317376 (2017)

[13] Subramanian K, Nagarajan R, De Baets P, Subramaniam S, Thangiah W, Sukumaran J. Eco-friendly mono-layered PTFE blended polymer composites for dry sliding tribo-systems. Tribology International 102: 569-579 (2016)
[14] Palm oil research. http://www.palmoilresearch.org/statistics.html.

[15] Lagel M C, Hai L, Pizzi A, Basso M C, Delmotte L, Abdalla S, Zahed A, Al-Marzouki F M. Automotive brake pads made with a bioresin matrix. Industrial Crops and Products 85: 372-381 (2016)

[16] Kumagai S, Matsuo Y. Composite produced from rice husk and chopped carbon fiber without using any binders. Industrial Crops and Products 43: 640-647 (2013)

[17] Hayashi J I, Horikawa T, Takeda I, Muroyama K, Ani F N. Preparing activated carbon from various nutshells by chemical activation with $\mathrm{K}_{2} \mathrm{CO}_{3}$. Carbon 40(13): 2381-2386 (2002)

[18] Yahya M A, Al-Qodah Z, Ngah C Z. Agricultural bio-waste materials as potential sustainable precursors used for activated carbon production: A review. Renewable and Sustainable Energy Reviews 46: 218-235 (2015)

[19] Tahir N A M, Abdollah M F B, Hasan R, Amiruddin H. The effect of sliding distance at different temperatures on the tribological properties of a palm kernel activated carbonepoxy composite. Tribology International 94: 352-359 (2016)

[20] Zamri Y, Shamsul J B. Physical properties and wear behaviour of aluminium matrix composite reinforced with palm shell activated carbon (PSAC). Kovove Mater 49: 287-295 (2011)

[21] Yusoff Z, Jamaludin S B, Amin M, Zaidi N H A. Sliding wear properties of hybrid aluminium composite reinforced by particles of palm shell activated carbon and slag. Journal of Science and Technology 2(1): 79-96 (2010)

[22] Chua K W, Abdollah M F B, Ismail N, Amiruddin H. Potential of palm kernel activated carbon epoxy (PKAC-E) composite as solid lubricant: Effect of load on friction and wear properties. Journal Tribology 2: 31-38 (2014)

[23] Tabor D. Status and direction of tribology as a science in the 80s. In Proceedings of the International Conference Tribology in the 80s, NASA Lewis Research Centre, Cleveland, Ohio, 1983: 1-17.

[24] Frost H J, Ashby M F. Deformation Mechanism Maps: The Plasticity and Creep of Metals and Ceramics, First ed. Oxford, New York: Pergamon Press, 1982.

[25] Rasool G, Stack M M. Wear maps for TiC composite based coatings deposited on 303 stainless steel. Tribology International 74: 93-102 (2014)

[26] Lim S C, Ashby M F. Overview no. 55 wear-mechanism maps. Acta metallurgica 35(1): 1-24 (1987)

[27] Ashby M F, Lim S C. Wear-mechanism maps. Scripta Metallurgica et Materialia 24(5): 805-810 (1990)

[28] Standard Test Method for Wear Testing with a Pin-on-Disk Apparatus. ASTM G99-05 (2016) 
[29] Mahmud D N F, Abdollah M F B, Masripan N A B, Tamaldin N, Amiruddin H. Frictional wear stability mechanisms of an activated carbon composite derived from palm kernel by phase transformation study. Industrial Lubrication and Tribology 69(6): 945-951 (2017)

[30] Hatipoglu G, Kartal M, Uysal M, Cetinkaya T, Akbulut H. The effect of sliding speed on the wear behavior of pulse electro co-deposited Ni/MWCNT nanocomposite coatings. Tribology International 98: 59-73 (2016)

[31] Straffelini G, Pellizzari M, Maines L. Effect of sliding speed and contact pressure on the oxidative wear of austempered ductile iron. Wear 270(9): 714-719 (2011)

[32] Luo Q. Tribofilms in solid lubricants. Encyclopedia of Tribology 3760-3767 (2013)

[33] Chowdhury M A, Helali M. The effect of amplitude of vibration on the coefficient of friction for different materials. Tribology International 41(4): 307-314 (2008)

[34] Ding H H, He C G, Ma L, Guo J, Liu Q Y, Wang W J. Wear mapping and transitions in wheel and rail materials under different contact pressure and sliding velocity conditions. Wear 352: 1-8 (2016)

[35] Rao R N, Das S. Effect of sliding distance on the wear and friction behavior of as cast and heat-treated Al-SiCp composites. Materials \& Design 32(5): 3051-3058 (2011)

[36] Yousif B F. Frictional and wear performance of polyester composites based on coir fibres. Proceedings of the Institution of Mechanical Engineers, Part J: Journal of Engineering Tribology 223(1): 51-59 (2009)

[37] Sudheer M, Hemanth K, Raju K, Bhat T. Enhanced mechanical and wear performance of epoxy/glass composites with PTW/graphite hybrid fillers. Procedia Materials Science 6: 975-987 (2014)

[38] Yousif B F, El-Tayeb N S M. Tribological evaluations of polyester composites considering three orientations of CSM glass fibres using BOR machine. Applied Composite Materials 14(2): 105-116 (2007)

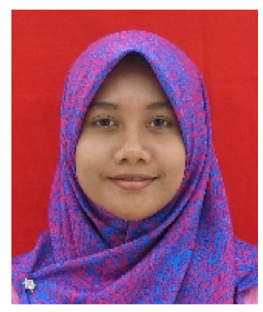

Dayang Nor Fatin MAHMUD. She is a MSc. student at the Universiti Teknikal Malaysia Melaka under
[39] Yousif B F, Lau S T, McWilliam S. Polyester composite based on betelnut fibre for tribological applications. Tribology international 43(1): 503-511 (2010)

[40] Yousif B F. Replacing of glass fibres with seed oil palm fibres for tribopolymeric composites. Tribology-Materials, Surfaces \& Interfaces 2(2): 99-103 (2008)

[41] Chand N, Dwivedi U K. Sliding wear and friction characteristics of sisal fibre reinforced polyester composites: Effect of silane coupling agent and applied load. Polymer Composites 29(3): 280-284 (2008)

[42] Hashmi S A R, Dwivedi U K, Chand N. Graphite modified cotton fibre reinforced polyester composites under sliding wear conditions. Wear 262(11): 1426-1432 (2007)

[43] Yousif B F, El-Tayeb N S. Adhesive wear performance of T-OPRP and UT-OPRP composites. Tribology Letters 32(3): 199-208 (2008)

[44] Nirmal U, Hashim J, Low K O. Adhesive wear and frictional performance of bamboo fibres reinforced epoxy composite. Tribology International 47: 122-133 (2012)

[45] Chin C W, Yousif B F. Potential of kenaf fibres as reinforcement for tribological applications. Wear 267(9): 1550-1557 (2009)

[46] Li X, Gao Y, Xing J, Wang Y, Fang L. Wear reduction mechanism of graphite and $\mathrm{MoS}_{2}$ in epoxy composites. Wear 257(3): 279-283 (2004)

[47] Schön J. Coefficient of friction and wear of a carbon fiber epoxy matrix composite. Wear 257(3): 395-407 (2004)

[48] Shuhimi F F, Abdollah M F B, Kalam M D A, Hasan M, Mustafa A, Amiruddin H. Tribological characteristics comparison for oil palm fibre/epoxy and kenaf fibre/epoxy composites under dry sliding conditions. Tribology International 101: 247-254 (2016)

[49] Zhang Z, Breidt C, Chang L, Haupert F, Friedrich K. Enhancement of the wear resistance of epoxy: Short carbon fibre, graphite, PTFE and nano- $\mathrm{TiO}_{2}$. Composites Part A: Applied Science and Manufacturing 35(12): 1385-1392 (2004)

the supervision of Mohd Fadzli Bin Abdollah. Her research field includes tribology of eco-materials. 


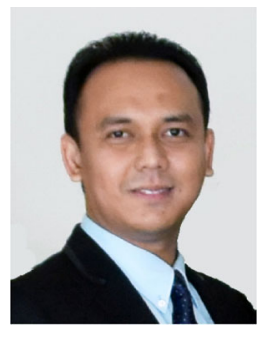

Mohd Fadzli Bin ABDOLLAH. He received his B.Eng. (Hons.) and M.Eng. degrees in mechanical engineering from Universiti Kebangsaan Malaysia in 2004 and 2005, respectively. Later in 2011, he received his $\mathrm{PhD}$ degree in tribology from
Nagoya University, Japan. His current position is an associate professor and the deputy dean (Research \& Postgraduate Studies) in the Faculty of Mechanical Engineering, Universiti Teknikal Malaysia Melaka. His research area includes tribology of eco-materials and surface engineering. 